\title{
Big Data Analysis of the \#BringBackOurGirls Cyber-Campaign
}

\author{
Maria Teresa García Català \\ UNIVERSITAT OBERTA DE CATALUNYA (UOC)
}

mgarciacat便uoc.edu

Received: 15/09/2019

Accepted: 25/03/2020

\begin{abstract}
We used a web tool to extract Twitter API data on the \#BringBackOurGirls campaign. The Twitter hashtag was used for a campaign denouncing the kidnapping of 276 schoolgirls in Chibok, Nigeria on the $14^{\text {th }}$ of April 2014 by the Jihadist group Boko Haram. The data extracted covered the period spanning from the creation of the campaign (19 $9^{\text {th }}$ of May 2014) to the $16^{\text {th }}$ of May 2019. The data were anonymous because they were provided in aggregate form, covering things such as: the number, content, and chronology of tweets; information on geographical area; the relevance of the users making comments; information on followers; the impact of tweets; 'likes'; re-tweets; demographic profiles (gender); keyword information. These indications were provided in the form of mass, open data by Twitter's API. The data was ordered and analysed by the research team during the course of the qualitative study to shed light on the cyber-campaign.
\end{abstract}

Keywords: hashtag, \#BringBackOurGirls, Boko Haram, Chibok, Jihadism, Africa.

Corresponding author: Maria Teresa García Català. Universitat Oberta de Catalunya (UOC), Av. del Tibidabo, 39, 08035, Barcelona (Spain).

Suggested citation: García Català, M.T. (2020). Big Data Analysis of the \#BringBackOurGirls Cyber-Campaign. Debats. Journal on Culture, Power and Society, 5, 261-270. DOI: http://doi.org/10.28939/iam.debats-en.2020-15

\section{INTRODUCTION}

As noted in the Abstract, our data analysis is based upon the campaign run through the \#BringBackOurGirls Twitter hashtag. The hashtag was created on the $23^{\text {rd }}$ of April 2014 by Ibrahim M. Abdullahi, a Nigerian lawyer, to draw the world's attention to the kidnapping of 276 girls from a school in Chibok in the State of Borno in North-Eastern Nigeria. The kidnappings were carried out by Boko Haram, an Islamic terrorist group. Many public figures joined the campaign from around the world. These included: Michelle Bachelet (Chilean politician); Michelle Obama (President Obama's wife), Malala Yousafzai (a Pakistani activist); Ellen DeGeneres and Angelina Jolie (actresses), who played key roles in spreading word of the Twitter campaign abroad, giving it a much higher profile as they demanded the freeing of the kidnapped girls. Social media have been used in other conflicts since then, including in 'The Anglophone Crisis' (Ambazonia War - see map at Figure 4) in Cameroon in 2016 (Oriola, 2017). 
Here it is worth briefly contextualising the kidnappings leading to the cyber-campaign. Nigeria is a large, culturally and ethnically diverse West African nation. It is also geographically varied, with tropical rainforest in the south and savannah and semi-desert in the north. The country's GDP is the highest in the region thanks to a cornucopia of mineral resources (petroleum, natural gas, coal, tin, gold, bauxite, iron ore), and many agricultural products. The population has soared from 46 million in the 1960s to almost 196 million today (Nganji and Cockburn, 2020). Despite the country's natural riches, Nigeria's soaring population, endemic corruption, and bad governance have led to extremes of wealth and poverty, lack of social welfare, and a host of other problems. It is a nation of marked regional differences. Southern Nigeria is home to $50.8 \%$ of Christians and $1.4 \%$ of other religions. In Northern Nigeria, $50.4 \%$ of the population is Muslim - the fruit of a Southward spread of Islam from Sub-Saharan Africa. The Jihadist Boko Haram terrorist organisation has operated in Northern Nigeria since 2002. Boko Haram is allied to ISIL [Islamic State of Iraq and the Levant], whose goal is the creation of a Fundamentalist Islamic State (World Bank, 2019) under Sharia Law and to drive the population belonging to other religious groups further south. Since 2009, tensions in the area have led to an armed conflict in which over 20,000 people have already died. In just the last five years, over 10,000 women and girls have been kidnapped there, according to Human Rights Watch (HRW). The HRW report of the $30^{\text {th }}$ of April 2014 stated that many kidnapped women/girls were forced to marry members of the terrorist group, while others were sold for 2,000 Nairas (about US \$12.50 each) and sent to neighbouring countries such as Nigeria, Chad, and Cameroon. Although the kidnapping of the 276 schoolgirls in Chibok was far from an isolated incident, it proved to be a turning point, forcing Nigeria's Civil Society to react, sparking a storm of protest and actions around the world once the violence suffered by women in the country's conflicts became more widely known (Celso, 2015).

\section{METHODOLOGY}

In the study titled "Digital Communication as a Tool in the Fight Against Gender Violence in War Zones", of which this paper forms part, we analysed the \#BringBackOurGirls hashtag between its creation (May 2014) and May 2019. To ensure users' anonymity, we based our analysis on: (1) statistical values linked to the quantitative impact of Tweets - users' reactions through re-tweeting certain comments, videos, links or contents from tweets during specific periods, and ; (2) geo-location of users in order to grasp the world impact of the events covered and to detect significant behaviour patterns.

Figure 1 shows the impact of given tweets within a specified period (from the $4^{\text {th }}$ of August to the $12^{\text {th }}$ of August 2016), in which one can see users' activity/ reactions to specific tweets. Figure 2 shows the number of followers, re-tweets and tweets, and the impact of the \#BringBackOurGirls hashtag by geographical area during the same period. As we noted earlier, such information lets us see how the hashtag campaign spread from the local sphere to the global one, and to specific areas.

Figure 2 shows the number of followers, tweets, re-tweets, and the impact of this information by geographical area - data from which we obtained a map of the campaign's spread as reflected by users' activity in each zone.

The location data reveal that the campaign began as a local one and ended up as an international one. In other words, the greater part of the campaign's impact stemmed from the involvement of Nigerian citizens, with a total of 4729 tweets of which only 572 were published in Northern Nigeria (Kaduna, Katsina, Kano, etc.), an area in which roughly $50.4 \%$ of the country's population live. One can therefore say that mobilisation was much greater in Southern Nigeria. This seems odd because the kidnappings took place in Northern Nigeria. We shall now delve into this issue to consider possible explanations for this apparent regional disparity in response. 
Given that the geo-location data were not obtained from GPS sensors but rather from the information voluntarily supplied by users, one might suspect that many of those tweeting may have deliberately falsified their location (for example, by putting down made-up countries). Others may simply have left the location field blank. This is understandable given rational fears of being tracked down and suffering reprisals. One can therefore say that such geo-location information is unreliable and we have therefore excluded it from our analysis.

Figure 1 Specific tweets by days
Although the social network does not geo-localise its users, we noted that many of those expressing support for the kidnappers (rather than for their victims) chose to remain anonymous or to give the names of made-up countries in the 'location' field. We also saw that many of the users put down location data for all the countries they had lived in - information that helped us identify those members of the Nigerian diaspora who had spread the campaign from the host countries in which they are now living. Thus the geographic area from which their tweets were

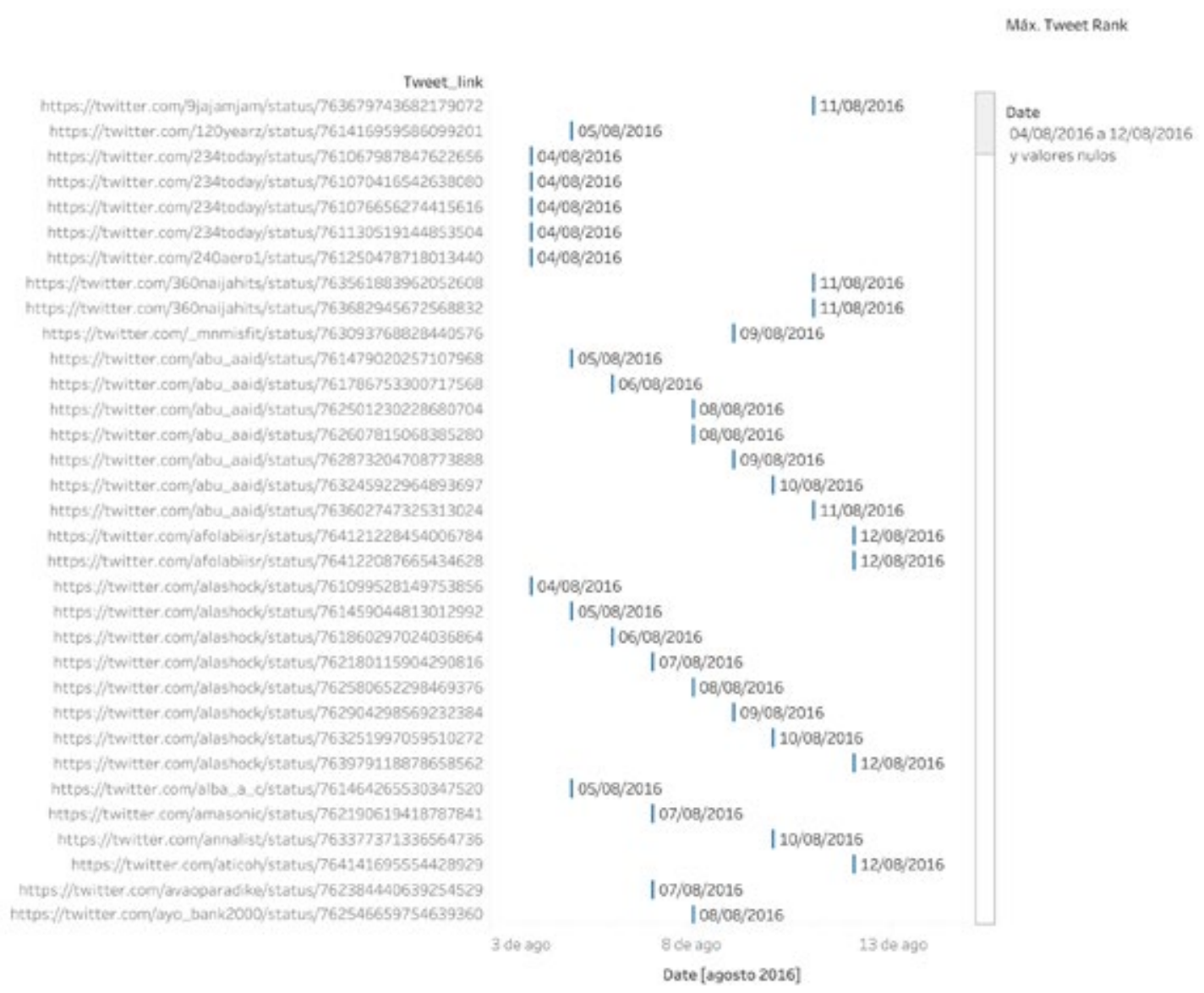


Figure 2 Number of followers, impact, tweets and re-tweets by geographical area

\#Bringbackourgirls

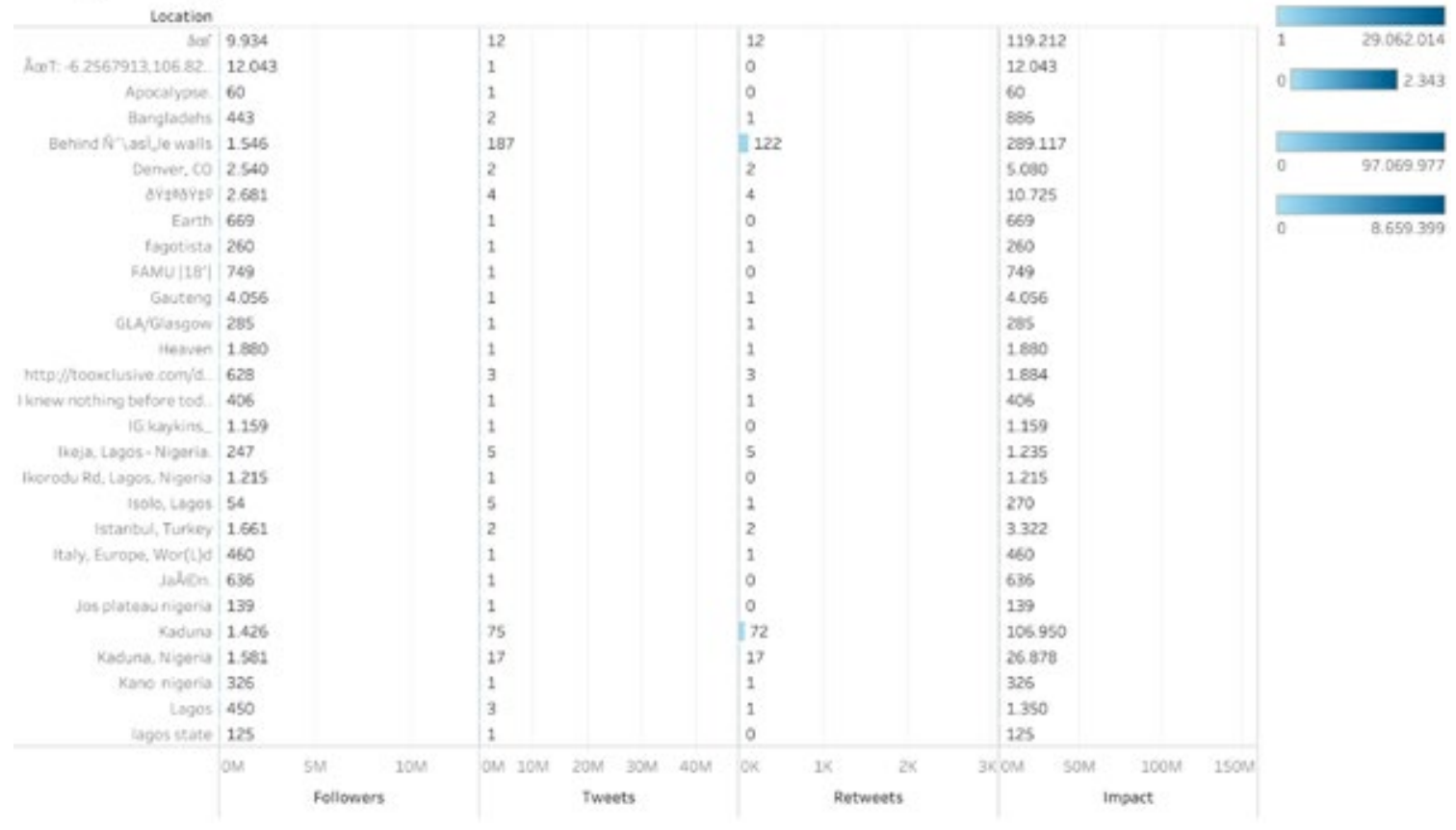

Figure 3 Nigerian citizens' participation in the campaign, broken down by cities

Nigerian localisation by areas

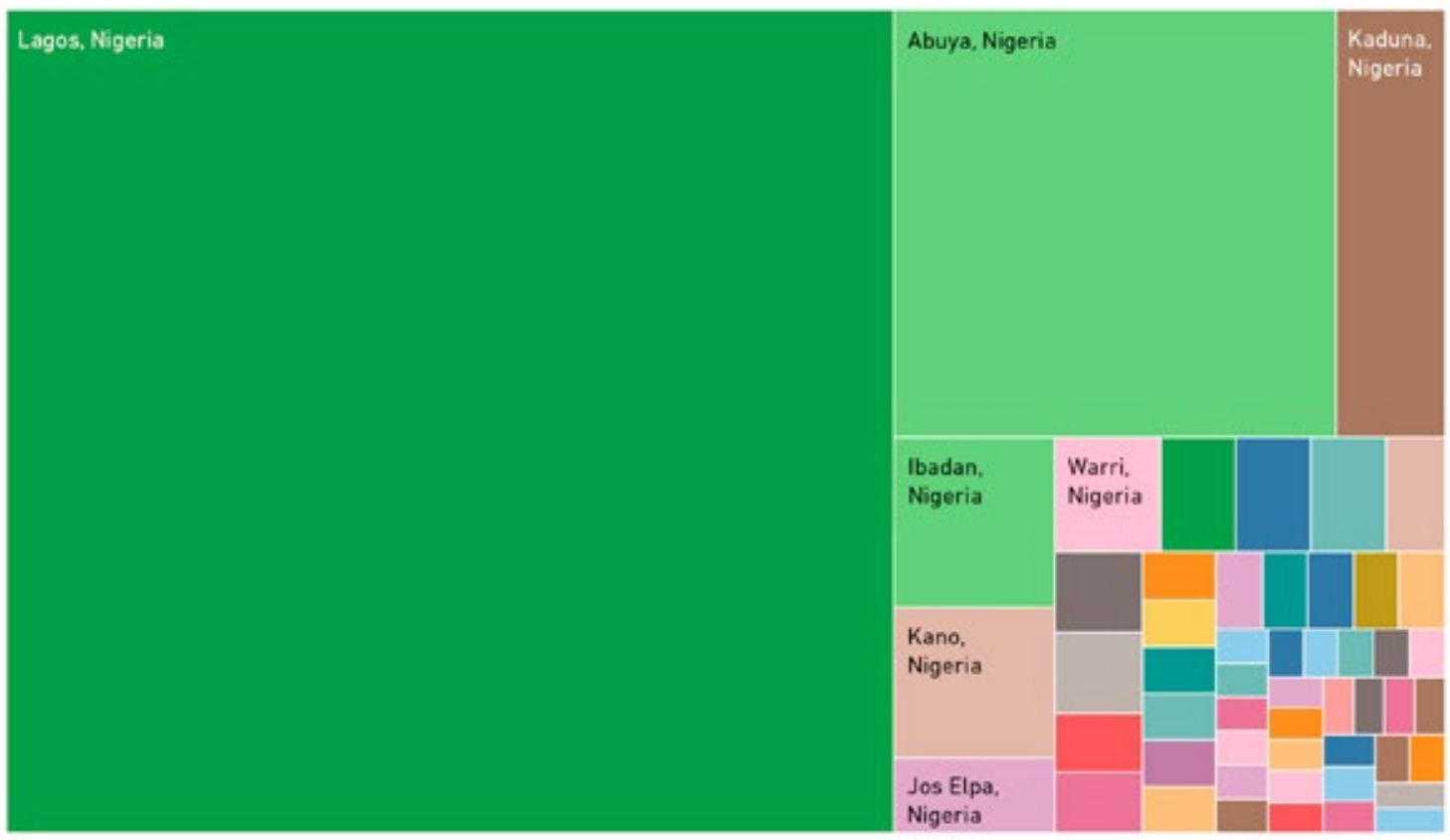


written helps us say to what extent this cyber-campaign influenced African emigrants living abroad, and to discover how many non-African users took part (that is to say, how the campaign spread to the rest of the world which — in principle — knew little or nothing of local circumstances in North-Eastern Nigeria).

Our analysis revealed that Nigeria was the country with the greatest number of tweets. The United States ran it a close second - possibly thanks to media coverage of the cyber-campaign by political celebrities in North America.
Figures 3 and 4 show those Nigerian cities in which there was most participation in the cyber-campaign. On the map in Figure 4, Chibok - the city where the kidnappings took place - is circled in blue. Abuja, Nigeria's present Capital — since 1991, succeeding Ikeja (1976-1991) —is circled in green. Lagos — the country's biggest city, financial heart, and the former Capital (1914-1976) — is where most tweets were published. Figure 4 shows the geographical break-down of tweets in North-South terms of the cities shown in Figure 3. The Southern cities such as Lagos and Ibadan, together

Figure 4 Map showing Nigerian citizens' participation by city

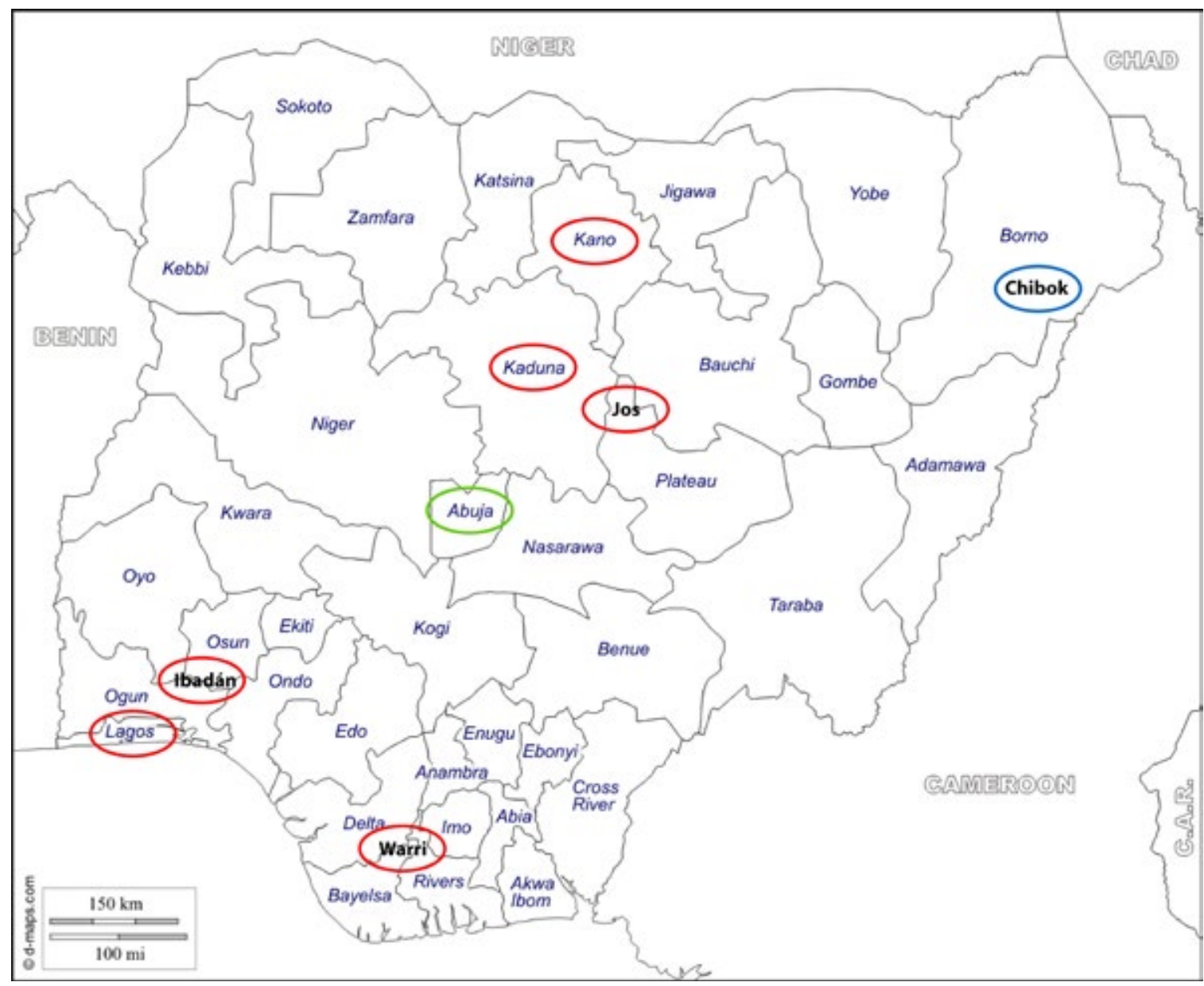


with the Capital (Central Nigeria) account for most of the country's Christians - the same faith as that of the kidnapped girls. Most of those taking part in the campaign were from these cities, where participation was even higher than in Chibok (Borno State), which is where the abducted schoolgirls were from.

Figure 5 shows users' tweets by country and geographical area, recording both the campaign's national and international repercussions. The information gleaned reveals that those involved in the campaign were drawn from Nigeria, people in other African countries (especially South Africa and Kenya), and at the international level, from The United States, Spain, and Canada as news of the Kenyan kidnappings reached their nations.
Another datum in our research on the \#BringBackOurGirls hashtag is the number of tweets published for each user account (that is to say, the number of tweets written by each individual). The figure was aggregated to maintain confidentiality. This information gives an idea of the spread of information and users' reactions to the kidnappings.

Figure 7 shows the trend in activity spanning the period between the hashtag's creation on the $19^{\text {th }}$ of May 2014, and the $28^{\text {th }}$ of June 2015. The graph shows the number of responses to a tweet, the number of re-tweets, the average number of tweets sent per user, and the total number of tweets. This information lets us contextualise the hashtag and see users' reaction to it.

Figure 5 Citizens' participation by regions and countries

\section{\#Bringbackourgirls localisation and re-tweets}

Localisation by area

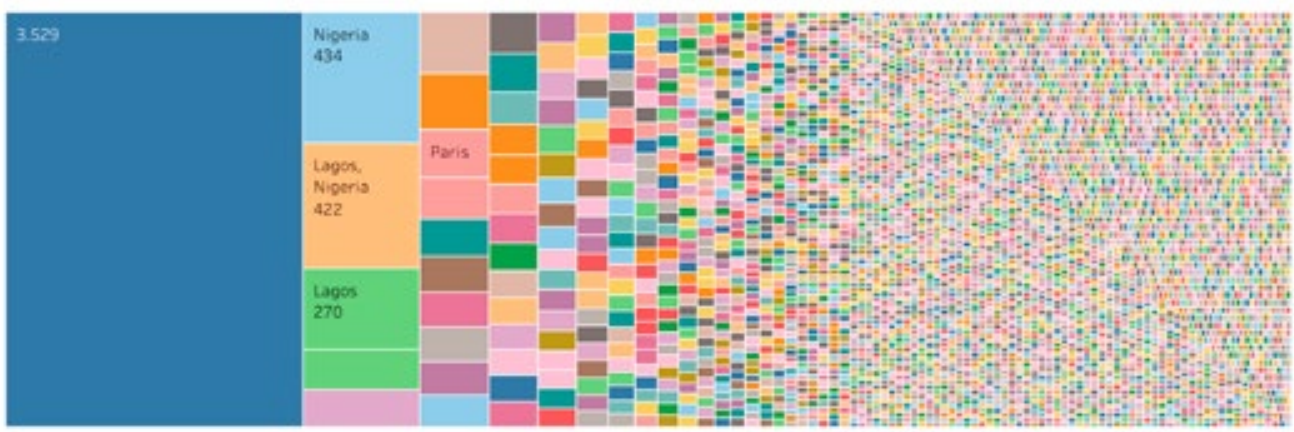

Localisation by country

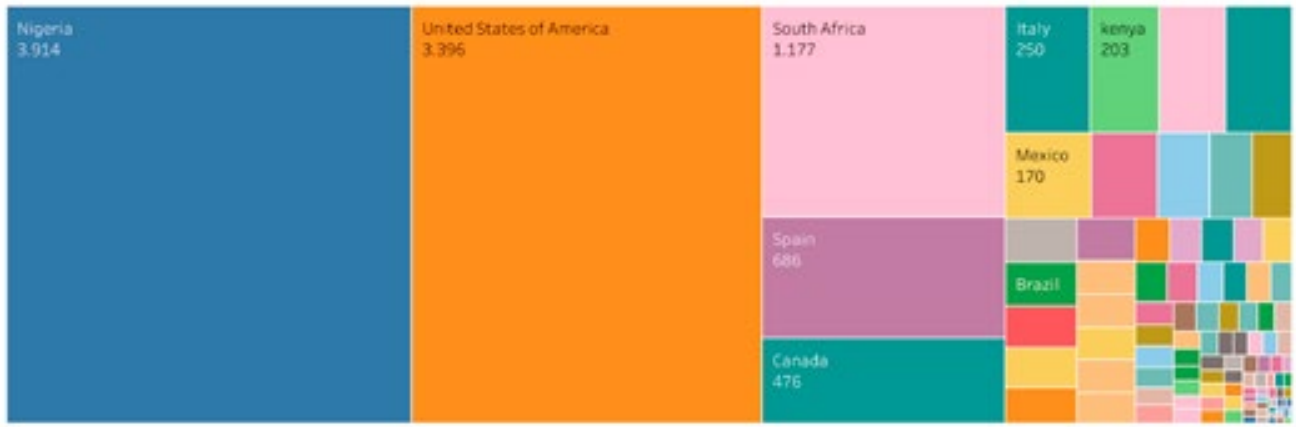


Figure 6 Number of contributions by user

\#Bringbackourgirls Tweets by number of users

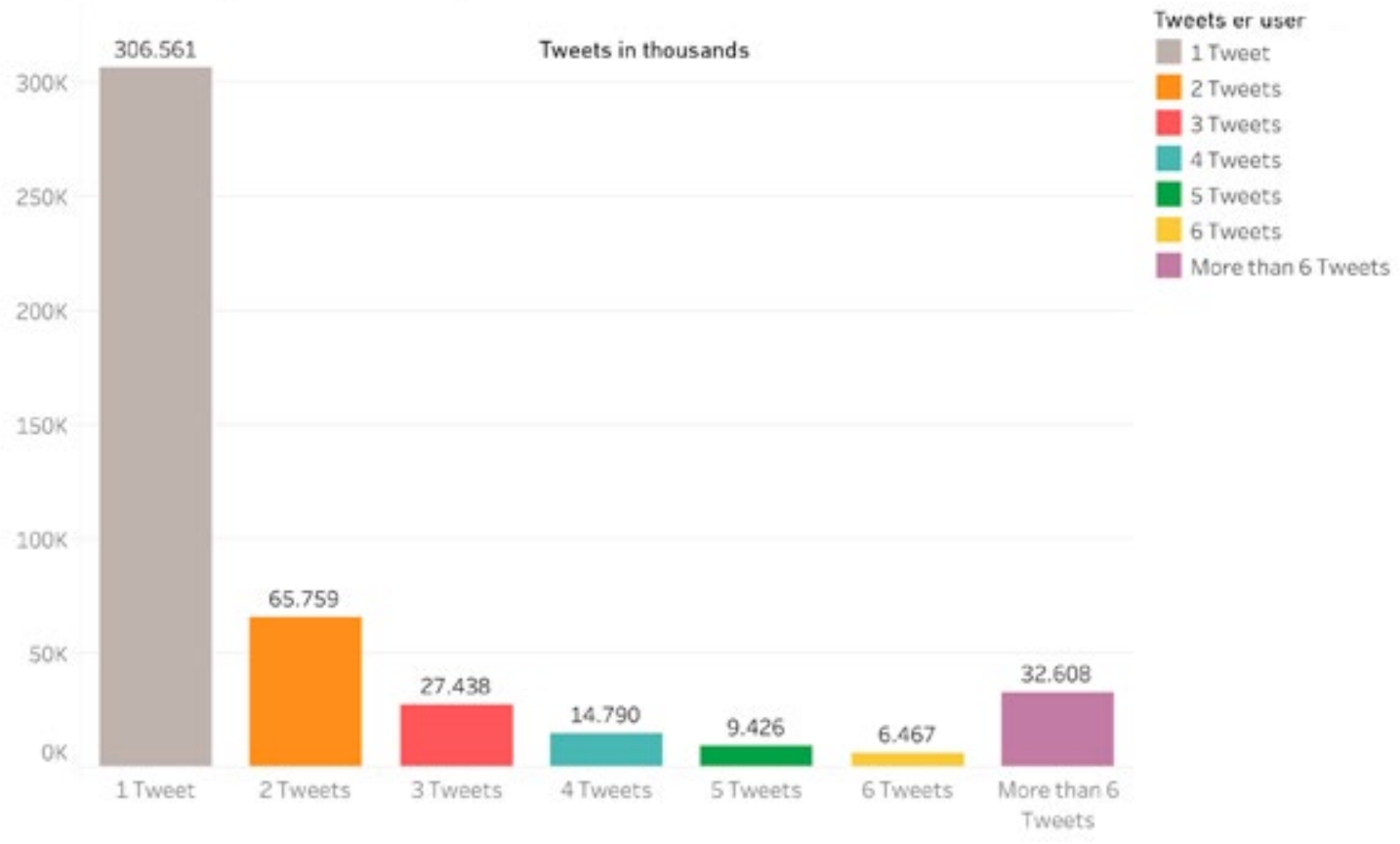

Figure 7 Hashtag activity on the $28^{\text {th }}$ of June 2015

\#Bringbackourgirls Activity 28/6/2015

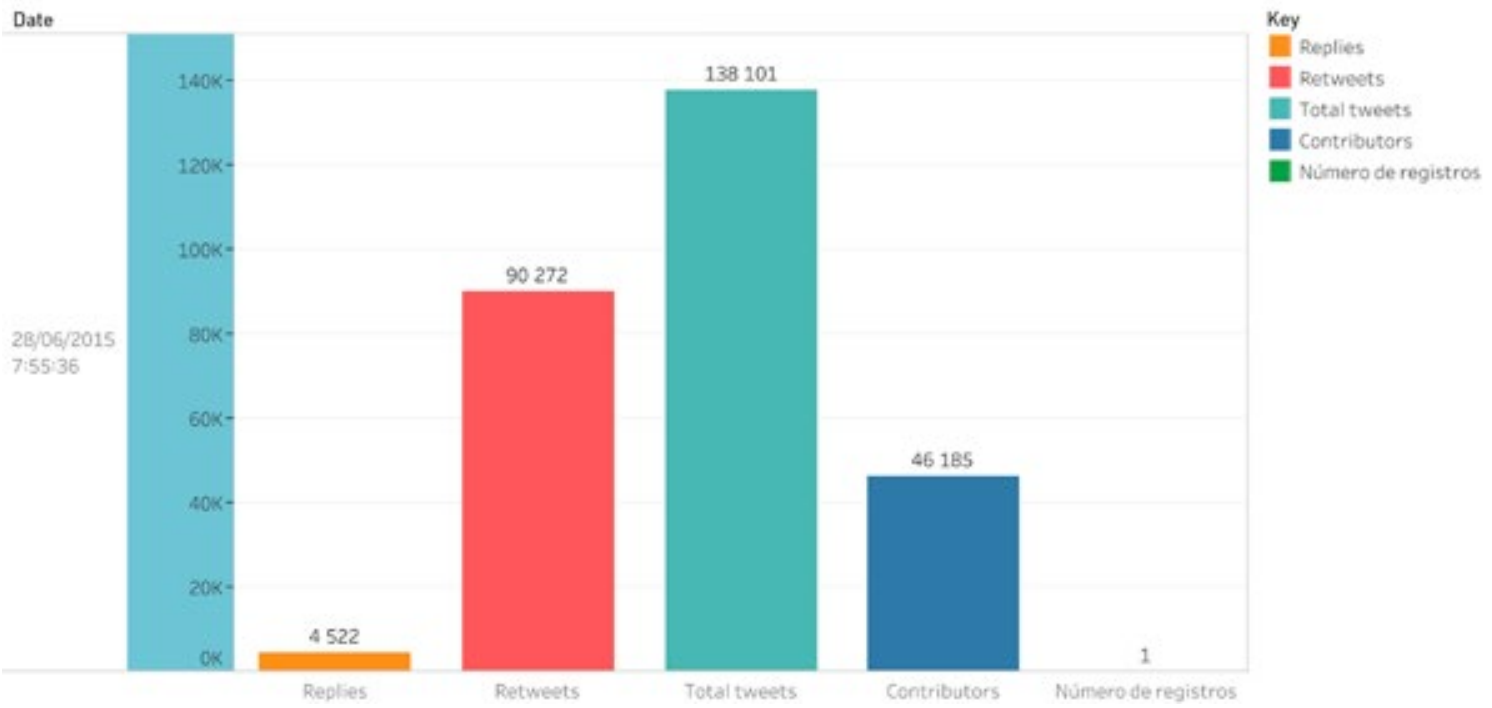


Among other things, Figure 8 shows the number of re-tweets in relation to the total number of tweets published by users in the period spanning from the $19^{\text {th }}$ of May 2014 to the $16^{\text {th }}$ of May 2019. This reveals the rate at which information was spread among users during this period. The speed with which information spread suggests the importance placed by users on the information in the tweets. Analysis of tweeting trends over the period also sheds light on the way the news spread. New events sparked heightened interest for a while, which then fell off. How long users stuck with the hashtag depended on their social commitment and the relevance of the news items.

Figure 9 analyses the hashtag's first year (2014), in which there was a large number of re-tweets, coinciding with the BBC's publication of the news that Boko Haram was forcing the kidnapped girls to fight for the terrorist group. This news strongly motivated users to respond, boosting the number of both tweets and re-tweets linked to the \#BringBackOurGirls hashtag. On the same lines, there were research articles analysing how the media covered stories on the terrorists' use of women in their war on the infidel (La and Pickett, 2019).

\section{CONCLUSIONS}

Throughout this analysis, we have used secondary data on a set of tweets sparked by the \#BringBackOurGirls cyber-campaign and its worldwide repercussions. The results reveal that the campaign grew from a local one to a global one, having an international impact. Nigerian citizens were the ones who took the greatest part in the campaign and of these, most of them belonged to the same ethnic group and/or the same religion as the kidnapped girls. We also noted

Figure 8 General activity spanning the period between the hashtag's creation on the $19^{\text {th }}$ of May 2014 and the $16^{\text {th }}$ of May 2019

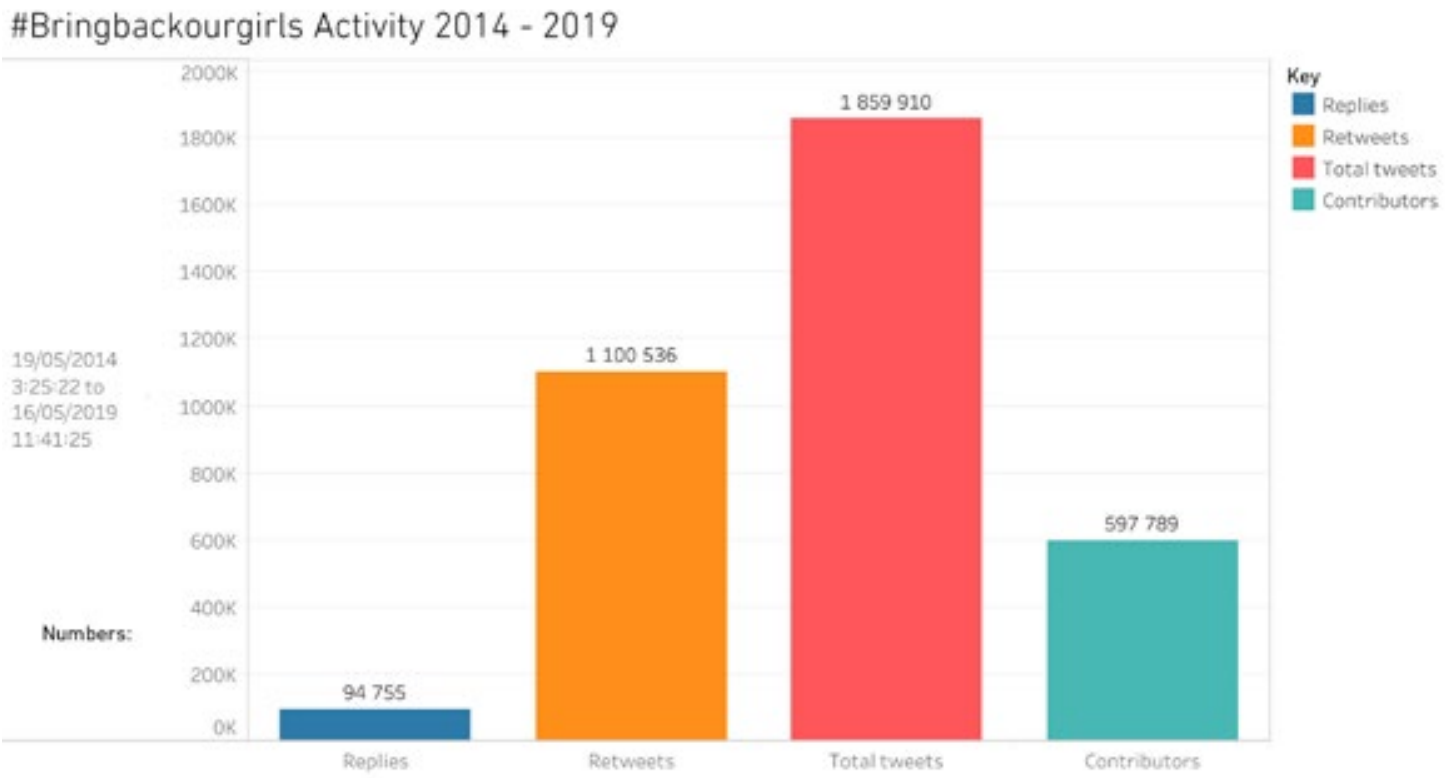


Figure 9 General re-tweeting during the hashtag's first year (2014)

\section{Re-tweet dates}
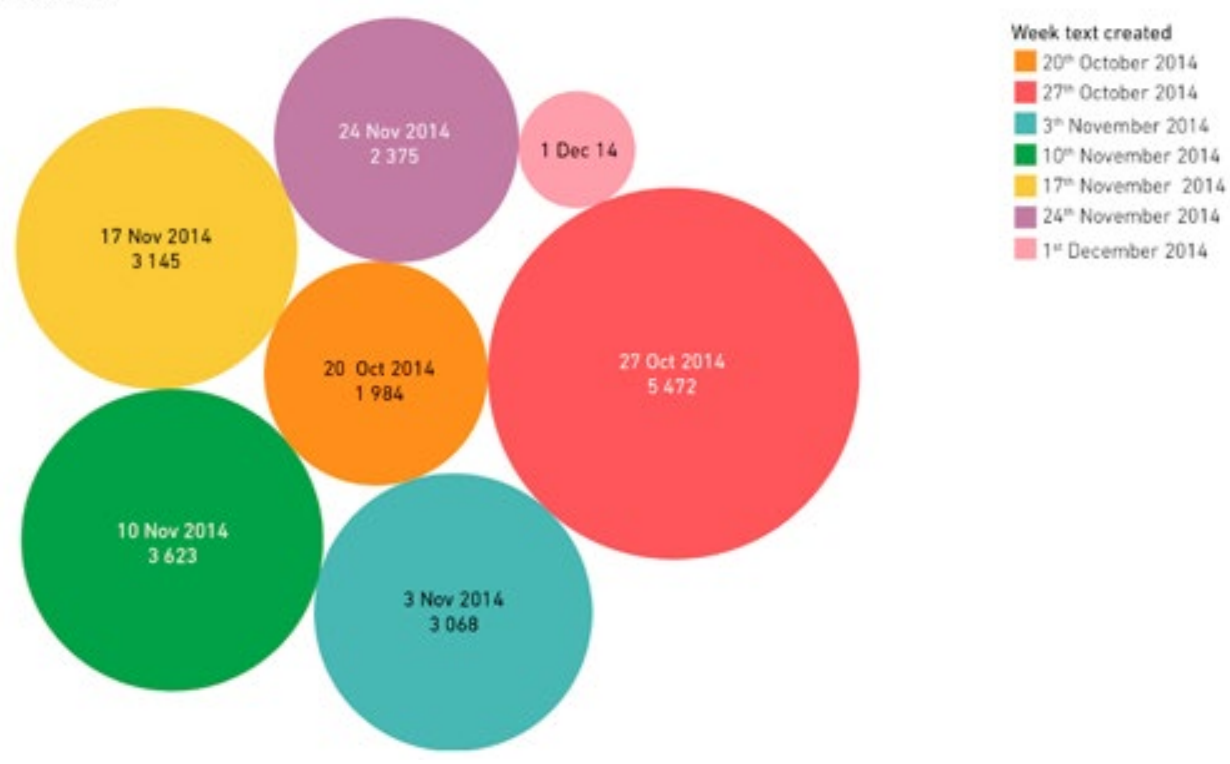

the unreliability of the geo-location data since it was provided by users themselves rather than from GPS. These data were rendered even more unreliable by the fact that many of those posting had reasons for hiding their identity and location - something that was especially true of those whose tweets supported the kidnappers. With regard to the statistical data, the fact that the volume of tweets held up throughout the period showed the keen interest sparked by the Chibok kidnappings both among Nigerian users and those from the rest of the world. The cyber-campaign's impact let us measure its path and all of the key moments at which the number of re-tweets peaked between May 2014 and May 2019 (see Figure 8). We also zoomed in on participation after these key points to capture the cyber-campaign's details.

\section{BIBLIOGRAPHIC REFERENCES}

Banco de datos mundial. (2019). [Accessed: $11^{\text {th }}$ October 2019]. https://datos.bancomundial.org/

Celso, A. N. (2015). The Islamic State and Boko Haram: Fifth Wave Jihadist Terror Groups. Orbis, 59, 249-268. DOI: 10.1016/j.orbis.2015.02.010

La, Hien and Pickett, S. (2019). Framing Boko Haram's Female Suicide Bombers in Mass Media: An Analysis of News Articles post-Chibok abduction. Critical Studies on Terrorism, 12(3), 512-532. DOI: 10.1080/17539153.2019.1599530

Nganji, J. T. and Cockburn, L. (2019). Use of Twitter in the Cameroon Anglophone Crisis. Behaviour \& Information Technology, 39 (3). DOI: 10.1080/0144929X.2019.1620333.

Oriola, T. B. (2017). “Unwilling Cocoons": Boko Haram's War Against Women. Studies in Conflict \& Terrorism, 40(2), 99-121. DOI: 10.1080/1057610X.2016.1177998 


\section{BIOGRAPHICAL NOTE}

Maria Teresa García Català (2020) has a Degree in Multi-media studies from UOC and in 2016 took a Master's Degree in Multi-media Applications, again at UOC. Her current research interests include studies facilitated by Big Data. 